\title{
The Effect of Friction Stir Welding Tool Wear on the Weld Quality of Aluminum Alloy AMg5M
}

\author{
Sergei Yu. Tarasov ${ }^{1,2, a)}$, Valery E. Rubtsov ${ }^{2, \text { b) }}$, and Evgeny A. Kolubaev ${ }^{1,2, c)}$ \\ ${ }^{1}$ National Research Tomsk Polytechnic University, Tomsk, 634050, Russia \\ ${ }^{2}$ Institute of Strength Physics and Materials Science SB RAS, Tomsk, 634055, Russia

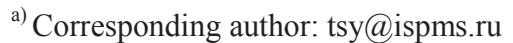 \\ b) rvy@ispms.ru \\ c) eak@ispms.ru
}

\begin{abstract}
Friction stir welding (FSW) tool wear has been studied from the standpoint of tribological layer generation and interaction of this layer with the tool's metal. It was shown that during FSW on aluminum alloy the latter adheres to the tool's working surface and then iron/aluminum reaction diffusion is initiated under the conditions of high mechanical stress and temperature. Since diffusion along the former austenite grain boundaries is much faster than volume diffusion, an intermetallic compound is formed inside the tool's metal thus causing embrittlement and pulling out the tool's metal fragments.
\end{abstract}

Keywords: friction stir welding, wear, tool

\section{INTRODUCTION}

Wear of FSW tool is a very important factor for obtaining the quality FSW joints since the tool worn beyond tolerance is not capable of good intermixing the welded metal thus forming linear defect like kissing bonds or Lazy S. Another aspect of the FSW tool wear is that wear particles are produced which then intermix with the joint metal and impair the joint strength. Therefore it is of interest to study the FSW tool wear mechanisms especially for highmelting point metals [1-3]. However, FSW of aluminum alloys proves to be also sensitive to the FSW tool wear.

From the tribology point of view, the FSW process conditions may be characterized as high-load, high speed sliding with adhesive interaction between hard and soft severely deformed material. Tribological testing under these conditions are always accompanied by generation of tribological layers by mechanical mixing [4] or shear instability $[5,6]$. This layer is characterized by nanosized grain subgrain structure and strong adhesion to the surfaces. Similar layers may be formed during FSW which then define its main wear mechanism as the adhesive one. The results reported [1] support such a conclusion together with the addition that diffusion wear being specific to the FSW process especially for high-melting point materials such as titanium alloys.

The objective of this work is to study wear mechanisms in steel FSW tools for welding aluminum alloy.

\section{MATERIAL AND INVESTIGATION PROCEDURE}

Annealed AMG5M aluminum alloy sheet $5 \mathrm{~mm}$ thickness sheets have been welded using a FSW machine developed and built at Cheboksary plant "Sespel". This alloy structurally consists of aluminum/magnesium solid solution and inclusions basically being $\mathrm{Mg}_{2} \mathrm{Si}$ and $\mathrm{Al}_{6} \mathrm{Mn}$. The FSW tool had shoulder diameter $19 \mathrm{~mm}$ and pin diameter $6 \mathrm{~mm}$. Weld path length was $2000 \mathrm{~m}$ at $560 \mathrm{rpm}$, plunge force $2600 \mathrm{~kg}$, feed rate $500 \mathrm{~mm} / \mathrm{min}$.

The SEM instrument Carl Zeiss EVO-50 attached with EDX equipment X-act (Oxford Instruments) has been used for detecting the chemical composition of the FSW tool and tribological layers.

International Conference on Physical Mesomechanics of Multilevel Systems 2014

AIP Conf. Proc. 1623, 635-638 (2014); doi: 10.1063/1.4901501

(C) 2014 AIP Publishing LLC 978-0-7354-1260-6/\$30.00 


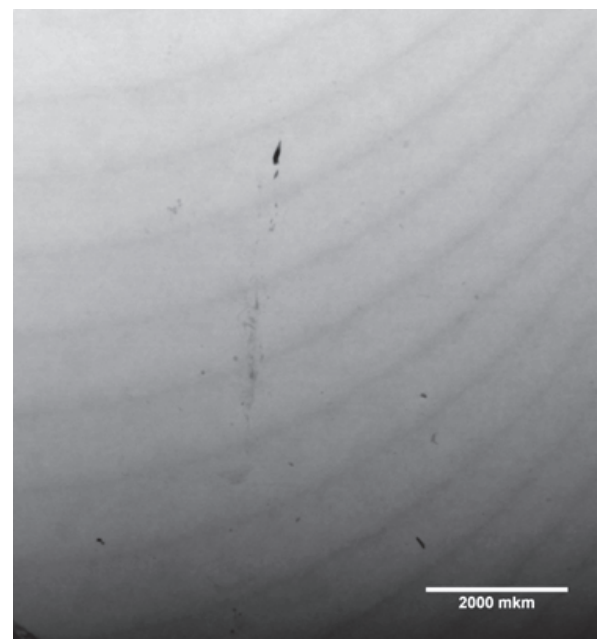

FIGURE 1. Radiography image of FSW joint showing inclusions

The metallographic characterization has been carried out using optical microscope on samples etched by a solution of 5 vol.\% nitric acid in ethyl alcohol. Microfocus X-ray tube XWT 240 SE (X-RAY WorX, Garbsen, Germany) and flat panel detector XRD 1622 AP3 (PerkinElmer, Waltham, USA) courtesy of ZAO Testron (SaintPetersburg) have been used to achieve 40x geometrical magnification in radiography of FSW bead.

\section{RESULTS AND DISCUSSION}

The example of high-geometrical magnification radiography image in Fig. 1 shows the presence of irregular inclusions in the weld metal which can be the FSW tool's wear particles of different compositions. These particles may serve as stress concentrators during mechanical loading and thus reduce the strength of the joint.

To study the wear particles formation during FSW we examined the worn surface of the FSW tool made of 1.2344 X40CrMoV5-1 steel after welding total seam length $2000 \mathrm{~m}$. First of all we can state that the working surface of this tool is covered by patches of white metal including both the pin's and shoulders' surfaces. Also one of the shoulder's grooves is fully filled with this metal. When examining the polished and etched FSW tool cross section view, we find at least four different types of deposits. The most dangerous one is shown in Fig. 2 which contains the tool's metal particles detached from the tool (Fig. 2(a)).

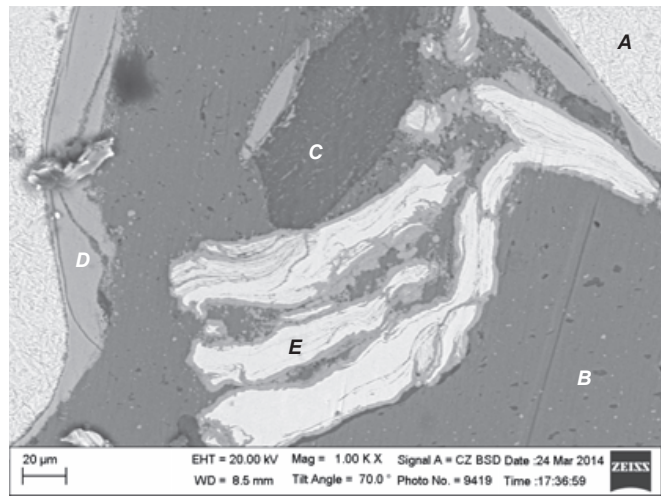

(a)

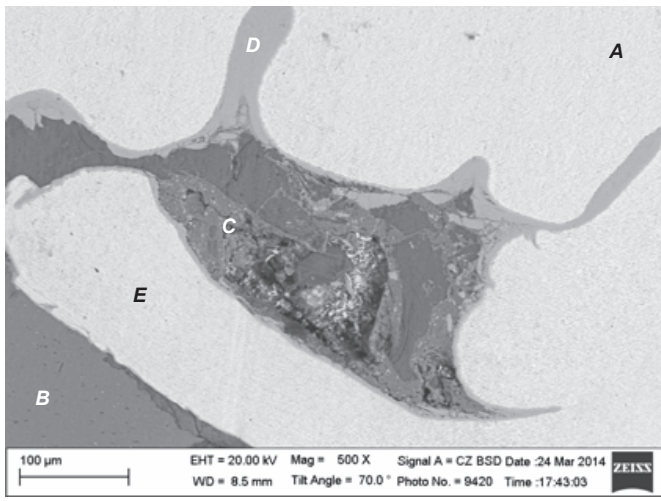

(b)

FIGURE 2. The wear particle formation in the FSW tool by reactive diffusion of iron into aluminum: $A-$ steel, $B$ - mechanically mixed aluminum alloy, $C$ - mechanically mixed layer enriched by oxides and silicides, $D$ - IMC, $E$ - wear particles 


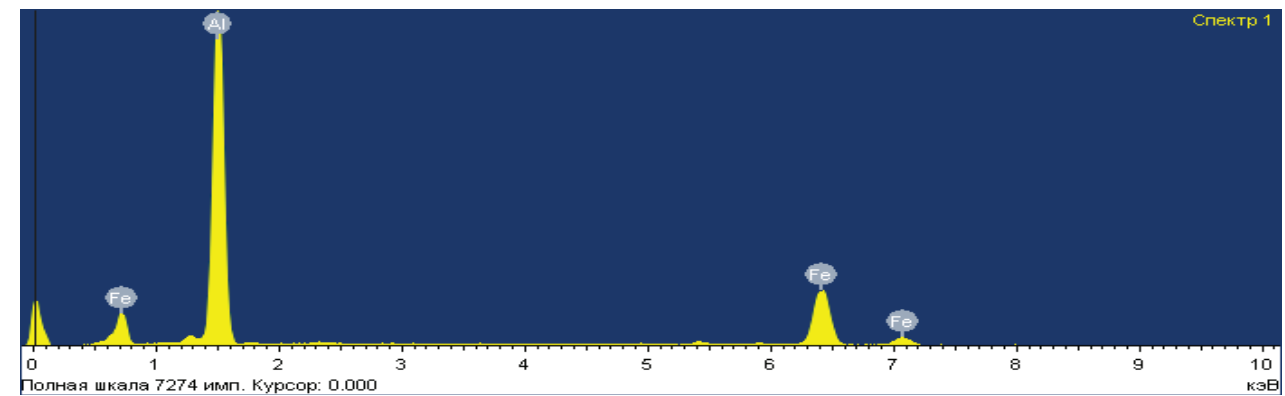

\begin{tabular}{cccc}
\hline Element & Intensity Factor & wt. \% & at. \% \\
\hline Al K & 0.8001 & 59.40 & 75.18 \\
Fe K & 0.9190 & 40.60 & 24.82 \\
Total & & 100.00 & \\
\hline
\end{tabular}

(a)

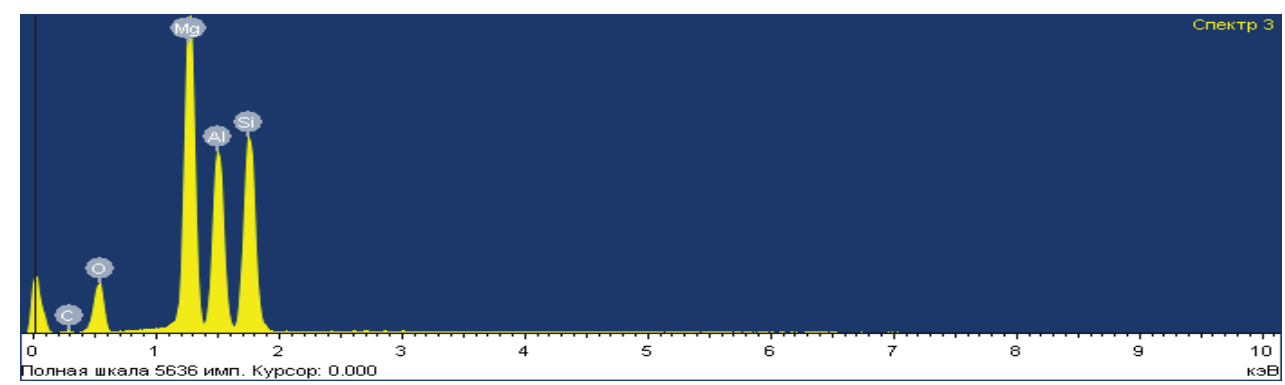

\begin{tabular}{lccc}
\hline Element & Intensity Factor & wt.\% & at.\% \\
\hline C K & 0.1885 & 6.45 & 11.47 \\
O K & 0.7633 & 23.91 & 31.95 \\
Mg K & 1.0612 & 25.21 & 22.16 \\
Al K & 0.7271 & 19.12 & 15.15 \\
Si K & 0.6541 & 25.31 & 19.26 \\
Total & & & \\
\hline
\end{tabular}

(b)

FIGURE 3. The EDS spectrum and concentration of elements in zones $D$ (a) and $C$ (b) shown in Fig. 2

Earlier stage of wear particle generation is shown in Fig. 2(b) where we can see the modified metal tongues inside the tool's metal. When analyzing the chemical composition of these tongues by EDS we find them to be the intermetallic compound (IMC) $\mathrm{FeAl}_{3}$ (see zone $D$ in Fig. 2 and EDS spectrum in Fig. 3(a)). As follows from the literature sources [7-10] such an IMC layer may be formed due to diffusion of iron atoms into aluminum. The IMC layer was found to cover the FSW tool working surface as a thin film but in some places it penetrated deep inside the steel plausibly along the former austenite grain boundaries or by Kirkendall voids formed at the diffusion front due to faster iron atom diffusion in aluminum [10].

The EDS spectra and concentrations of elements relating to zones in Fig. 2 are shown in Fig. 3. We can see here that the deposits are very inhomogeneous by their composition. Zone $B$ consists mostly of aluminum alloy admixed with the oxides and silicides while zone $C$ is composed mainly of oxides and silicides with lower concentration of aluminum (Fig. 3(b)). Zone $D$ atomic concentration Fe/Al ratio corresponds to that of intermetallic compound $\mathrm{FeAl}_{3}$. 
Discussing obtained results we can say that FSW steel tool has strong adhesion to the mechanically mixed and severely deformed aluminum alloy so that the diffusion of iron into this aluminum layer becomes feasible. It is worthwhile to note that the IMC formation by iron-to-aluminum diffusion has been reported elsewhere [7-10] for different welding processes including steel-to-aluminum FSW. In the considered here case we found it responsible for the FSW tool wear and admixing the wear particles in the weld. The difference between the IMC formation during dissimilar steel-to-aluminum FSW and inside the FSW tool is that in the first case only small spike-like instabilities on the diffusion front have been observed while we found the IMC deep inside the steel. The possible reason may be high contact pressure of the welded metal on the tool's surface and more intense grain boundary diffusion. At the same time the tongue-like shape of the IMC formations inside the steel tool demonstrates also the important role of volume diffusion.

It is known that $\mathrm{FeAl}_{3}$ intermetallic compound is rather brittle and, therefore, it may be the reason behind the wear particle formation in the FSW tool by the grain boundary embrittlement.

Inclusions shown in Fig. 1 differ by their contrast and therefore by attenuation with respect to X-rays. The dark and gray ones could be either steel or mechanically mixed layer particles detached from the FSW tool surface.

\section{CONCLUSION}

1. During the FSW of aluminum alloy steel FSW tool is coated by tribological mechanically mixed layers. These layers are very inhomogeneous by composition and found to be consisting of mixture of aluminum alloy particles, oxides and silicides. In the vicinity of the tool's surface there is a layer of $\mathrm{Fe}-\mathrm{Al}_{3}$ intermetallic compound of both continuous and spiked morphology.

2. Intensive volume and grain boundary diffusion of iron into aluminum alloy tribological layers is the reason for formation of $\mathrm{Fe}-\mathrm{Al}_{3}$ intermetallic compound along the former austenite grain boundaries in the tool. This reaction diffusion serves to embrittle the grain boundaries.

3. The fragments of the FSW tool material are deformed and detached from the FSW tool by the embrittled grain boundaries under the shear stress developed on the surface of the tool during FSW.

\section{ACKNOWLEDGEMENT}

The work has been supported by Program for Basic Scientific Research of the State Academy of Science on 2013-2020 and RF Ministry of Education and Science (Contract No. 02.G25.31.0063) in the framework of RF Government Order No. 218.

\section{REFERENCES}

1. B. T. Thompson and S. S. Babu, Application of Diffusion Models to Predict FSW Tool Wear: Proceedings of XXI Int. Offshore and Polar Engineering Conf., Maui, Hawaii, USA, June 19-24, 2011 (Maui, Hawaii, USA, 2011), p. 520.

2. T. Prater, A. Strauss, G. Cook, B. Gibson, and Ch. Cox, J. Mater. Eng. Perform. 22, 1807 (2013).

3. B. Thompson and S. S. Babu, Weld. Res. 89, 256 (2010).

4. D. A. Rigney, Wear 245, 1 (2000).

5. V. E. Rubtsov, S. Yu. Tarasov, and A. V. Kolubaev, Phys. Mesomech. 15(5-6), 337 (2012).

6. S. Tarasov, V. Rubtsov, and A. Kolubaev, Wear 268, 59 (2010).

7. C. Maldonado, A. Medina-Flores, L. Bejar-Gomez, and A. Ruiz, Revista Mexicana de Fisica S 55(1), 130.

8. S. Bozzi, A. L. Helbert-Etter, T. Baudin, B. Criqui, J. G. Kerbiguet, Mater. Sci. Eng. A 527, 4505 (2010).

9. M. Watanabe, K. Feng, Y. Nakamura, and S. Kumai, Mater. Trans. 52(5), 953 (2011).

10. M. J. Rathod and M. Kutsuna. Weld. Res., 16 (2004). 